\title{
Ensuring Job Satisfaction for Managing People at Work
}

\author{
Md. Istiaque Hossain Molla
}

Lecturer, BIL, BRAC University, Dhaka, BANGLADESH

*Corresponding Contact:

Email: ishtiak57@gmail.com

Cell Phone: +8801911506833

\begin{abstract}
Job satisfaction is the most common word in an organization that represents one of the most complex areas facing today's managers when it comes to managing their employees. Job satisfaction is a psychological state of man when an individual's needs and aspirations fulfilled in a workplace, people are contented and happy with one's job. Satisfactory pay, autonomy challenging work, participation in decision making, supportive working conditions, supportive colleagues and participatory management all these are the common factors of job satisfaction. Studies have demonstrated an unusually high impact on the job satisfaction for the motivation of workers, while the level of motivation has an impact on productivity, and hence also on the performance of organizations. Unfortunately, in our region, job satisfaction has not still received the proper attention from neither scholars nor managers of various business organizations. Due to individual differences job satisfaction has become a diverse issue. All the facets of job satisfaction have to be understood and considered for sustaining people. Conflict with peers and superiors, being deprived of fair pay and career development opportunities, lack of recognition, alienation are the vital causes of job dissatisfaction which adversely affects the quality of work and ultimately leads to organizational instability. Positive feedback, recognition, fair pay and other benefits, rewards, participation in decision making, congenial working conditions provide job satisfaction that contributes sustaining and retaining people in an organization. In fact there is no final definition of what career represents.
\end{abstract}

Key Words: Job satisfaction, Motivation, Human Resource Management

\section{INTRODUCTION}

Job satisfaction is an inevitable concern, a challenge for modern organizations. Today people search for organizations where they can have a voice and be recognized for their personal contribution in a supportive working environment. Different authors have different approaches towards defining job satisfaction.. Hoppock defined job satisfaction as any combination of psychological, physiological and environmental circumstances that cause a person truthfully to say I am satisfied with my job (Hoppock, 1935:47). According to this approach although job satisfaction is under the influence of many external factors, it 
remains something internal that has to do with the way how the employee feels. That is job satisfaction presents a set of factors that cause a feeling of satisfaction. Vroom in his definition of job satisfaction focuses on the role of the employee in the workplace. Thus he defines job satisfaction as affective orientations on the part of individuals toward work roles which they are presently occupying (Vroom, 1964:99). Employees' immediate supervisor has a great impact on their value systems fit with the organization and their level of job satisfaction (Howe 2003). Job is a means of acquiring the income to support a valued way of life (Weightman 1999:180). The happier people are within their job, the more satisfied they are said to be (Wikipedia). Job satisfaction does seem to be an attitude of mind and is undoubtedly an internal state associated with a feeling of achievement (Weightman 1999:191-192). Job satisfaction is a pleasurable feeling that "results from the perception that one's job fulfills or, allows for the fulfillment of one's key job values." This definition reflects three important aspects of job satisfaction. First, job satisfaction is a function of values defined as "what a person consciously or unconsciously desires to obtain."

Second, Job satisfaction represents a combination of positive or negative feelings that workers have towards their work. Meanwhile, when a worker employed in a business organization, brings with it the needs, desires and experiences which determinate expectations that he has dismissed. Job satisfaction represents the extent to which expectations are and match the real honor. Job satisfaction is closely related to the individual's behavior in the work place (Davis et al., 1985:109). Different employees have different views of which values are important, which is critical in determining the nature and degree of their job satisfaction.

Third, due to perceptual difference different people may view the same situation differently (Hollenbech and Wright 1996: 235-236). In fact, job satisfaction is mainly a psychological issue which if expressed verbally or through employee behavior can be understood by all concerned and be measured. The most common way of measurement is the use of rating scales where employees report their reactions to their jobs. Questions relate to the rate of pay, work responsibilities, variety of tasks, promotional opportunities, the work itself and co-workers (Wikipedia).

The objective of the paper is 'Through realizing job satisfaction different people at work could be managed spontaneously without much hassle and work with satisfaction' The ultimate objective of this paper is to provide job satisfaction measures that would enable the managers, practitioners and interested persons to understand, predict, interpret, analyze human behavior and make comprehensive arrangements for ensuring job satisfaction. The paper is based on the secondary material. Relevant books, website reading materials have been thoroughly analyzed and reviewed.

Section 1 of the study is the introductory part that delineates the theme of the paper namely 'job satisfaction' a crucial segment of human resources management. Section 2 refers to the factors which lead to job satisfaction. Section 3 indicates the various facets of job satisfaction. Part 4 deals with the causes responsible for job dissatisfaction. This section also gives indications on the negative impact of job dissatisfaction which may disrupt the equilibrium in the organization. In segment 5 the initiatives and measures have been discussed which would ensure and improve job satisfaction of people at work. Section 6 contains the concluding remarks.

\section{FACTORS OF JOB SATISFACTION}

The Society for Human Resource Management (SHRM) annually surveys employees and HR professionals about job satisfaction. The Top 5 Job Satisfaction Factors for Employees, are according to the 2009 Survey report: 
- Job Security

- $\quad$ Benefits

- Compensation/Pay

- Opportunities to use skills and abilities

- Feeling safe in the work environment

Job satisfaction is under the influence of a series of factors such as the nature of work, Salary, Advancement opportunities, Management, Work groups and Work conditions.

Rue and Byars suggested different approach regarding the factors of job satisfaction.

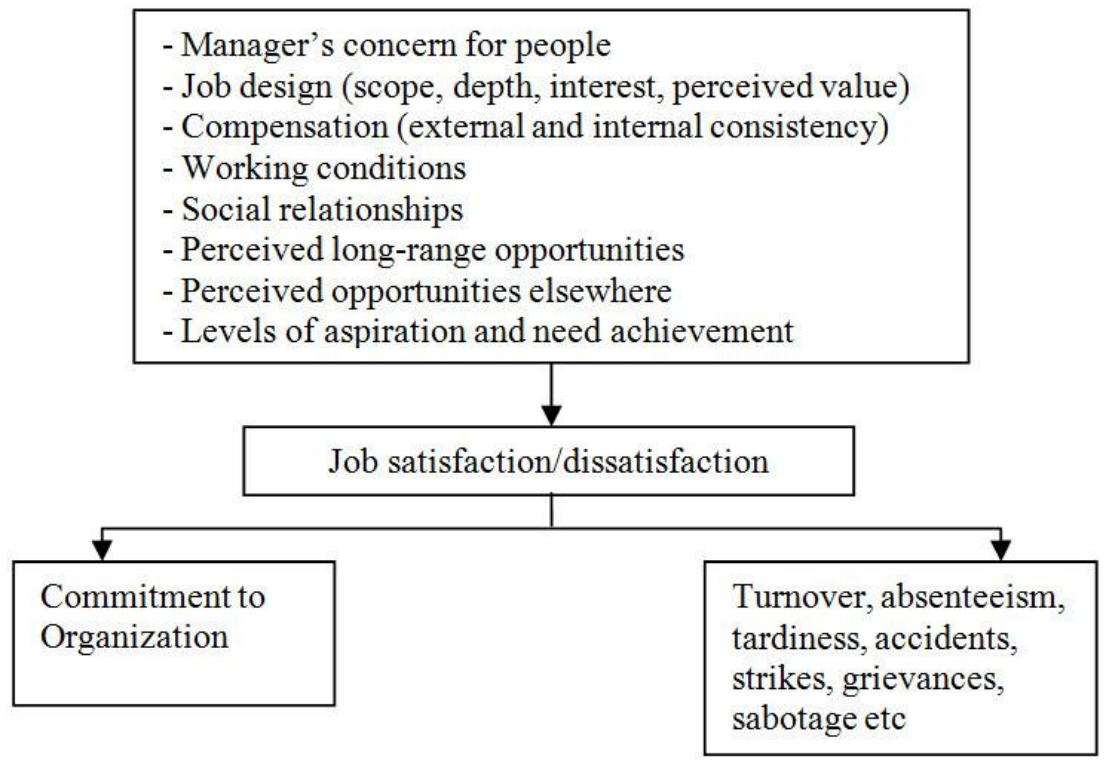

Figure 1: Determinants of satisfaction and dissatisfaction (rue and byars, 2003)

What makes a man satisfied at work? The answer refers to certain indicators which may also be the factors of job satisfaction.

- Important factors conducive to job satisfaction include mentally challenging work, equitable rewards, supportive working conditions and supportive colleagues. Commitment to organization and involvement with the organization and the actual job are also factors of job satisfaction.(Howe 2003).

- Basically job satisfaction depends on one's attitude and expectations; It is important how a man views his job, than the actual duties he performs. Wherever a person works the main issue is to understand the components of his job satisfaction.

- There are a variety of factors that can influence a person's level of job satisfaction; some of these factors include the level of pay and benefits, the perceived fairness of the promotion system within a company, the quality of the working conditions, leadership and social relationships, and the job itself (the variety of tasks involved, the interest and challenge the job generates, and the clarity of the job description/ requirements), management style and culture, employee involvement, empowerment and autonomous work groups (Wikipedia).

- Well designed job itself eventually results in job satisfaction. When the work to be done has a logic and makes sense to the job-holder. When the jobholder has contact with people using the service or product the job-holder is supplying. When job-holders take on more of the management of their jobs in deciding what to do, organizing their own time, solving their personal problems and controlling their own costs. When job-holders 
can discover more about how they are doing and whether their performance is improving or deteriorating (Hackman 1987)

According to Maslow (1954) human needs are food, air, rest, security, freedom from threat, affection, affiliation, recognition, status, achievement, competence, personal growth, the realization of potential, self-fulfillment. Maslow's hierarchy of human needs clearly indicates fulfillment of such needs motivate people. All these need satisfaction eventually leads to job satisfaction in a work situation. Therefore, the issue weather job satisfaction and job dissatisfactions are two opposite and excludable phenomena? There is no consensus regarding this issue among authors. Herzberg's Two Factor Theory is probably the most often cited point of view. In fact, the main idea is that employees in their work environment are under the influence of factors that cause job satisfaction and factors that cause job dissatisfaction. Therefore al factors that have derived from a large empirical research and divided into factors that cause job satisfaction (motivators) and factors that cause job dissatisfaction (hygiene factors), Table 1.

\begin{tabular}{|l|l|}
\hline Hygiene factors & Motivators \\
\hline Company policies & Achievement \\
\hline Supervision & Recognition \\
\hline Interpersonal relations & Work itself \\
\hline Work conditions & Responsibility \\
\hline Salary & Advancement \\
\hline Status & Growth \\
\hline
\end{tabular}

Job Satisfaction Factors (Herzberg, 1976)

- Various organizational factors which could be used to satisfy different needs: pay, pleasant work conditions, dining facilities, health and safety well monitored, job security, cohesive work group, friendly supervision, social recognition, job title, feedback from job itself, achievement in work (Steers and Porter 1991:35).

- Applied technology, sheer substantial scale, the sequence of work flow, working hours, ventilation, generated noise, maintenance of hygiene all of these influence the attitude and behavior of the people at work (Weightman 1999:179).

The importance of job satisfaction especially emerges to the surface if had in mind the many negative consequences of job dissatisfaction such a lack of loyalty, increased absenteeism, increase the number of accidents, etc. Spector (1997) lists three significant features of job satisfaction. First, organizations should be guided by human values. Such organizations are treating workers fairly and with respect. In such cases, the assessment of job satisfaction may serve as a excellent indicator of employee effectiveness. High levels of job satisfaction may be a sign of a good emotional and mental state of workers. Second, the behaviour of workers depending on their level of job satisfaction will affect the functioning and activities of the organization's business. From this, it can be concluded that job satisfaction will result in positive behaviour and vice versa, dissatisfaction from the work will cause in negative performance of employees. Third, job satisfaction may serve as indicators of organizational activities. Through job satisfaction evaluation, different levels of satisfaction in diverse organizational units can be defined, but in turn can serve as a good indication regarding in which organizational unit changes that would boost performance should be made. 


\section{MOdEL OF JOB SATISFACTION}

Christen, Iyer and Soberman (2006:137-150) provide a model of job satisfaction. The following elements are included in the model:

- Job-related factors,

- Role perceptions,

- Job performance and

- Firm performance.

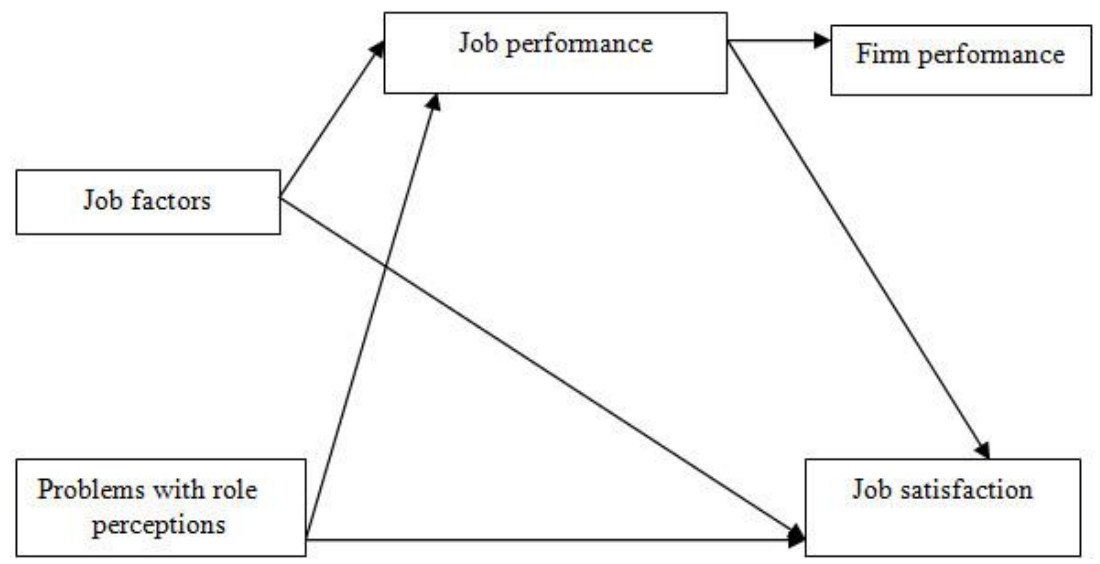

Figure 2: Christen, lyer and soberman model of job satisfaction (christen et, 2006).

Lawler and Porter (1967) give their model of job satisfaction that unlike the previous model places a special importance on the impact of rewards on job satisfaction, Figure 3.

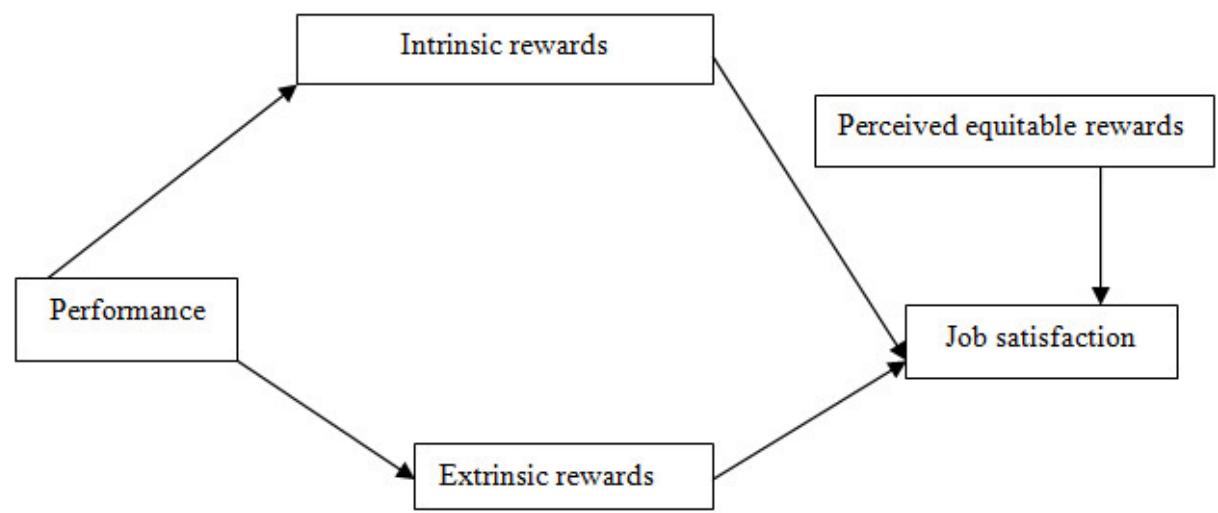

Figure 3: Lawler's and porter's model of job satisfaction (lawler and porter, 1967)

According to this model, the intrinsic and extrinsic rewards are not directly connected with job satisfaction, because of the employees' perceptions regarding the deserved level of pay.

Locke and Latham (1990) provide a somewhat different model of job satisfaction. They proceed from the assumption that the objectives set at the highest level and high expectations for success in work afford achievement and success in performing tasks. The analysis of success is: 


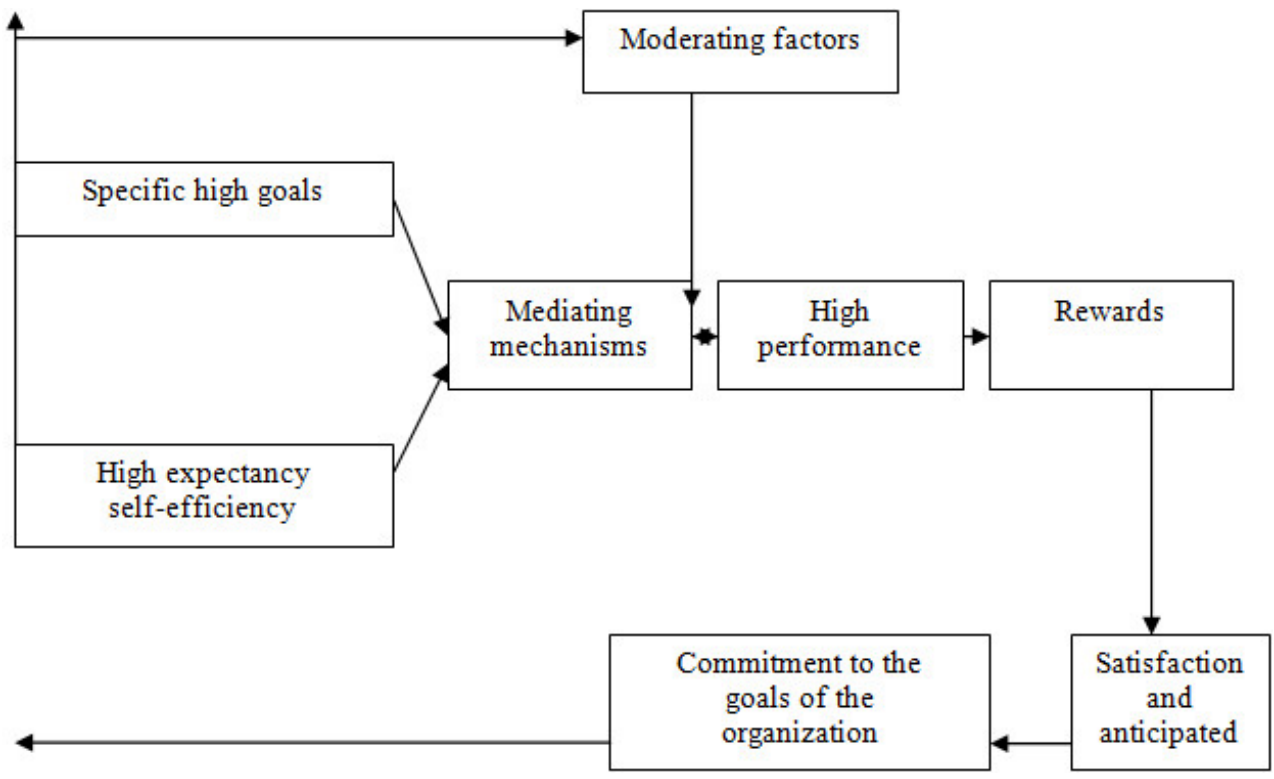

Figure 4: Locke and latham model of job satisfaction (locke and latham, 1990)

\section{Job-SATISFACTION A MULTI-DIMENSIONAL CONCEPT}

There are individual differences because we organise the incoming message into our stable view of the world we make it seem steady to us. But an individual's stable world is a different one from the other (Weightman 1999:24-25). Kelly (1955) introduced the idea that we all construct our worlds. We each see things differently and interpret things differently using our dimensions and models. It means we each construe the world differently.

Job-satisfaction is a virtual issue. It differs from person to person depending upon how one approaches his job. So there are various dimensions of job satisfaction which are discussed below:

- When an individual focuses primarily on the financial rewards, then the nature of the work may hold little interest for him. If a job with more pay comes his way, he will likely move on. In this case, money gives him job-satisfaction (Wikipedia).

- When an individual approaches work as a career then he will be interested in advancement and desire to climb the career ladder as far as possible. He will be then motivated by the status, prestige and power that come with the job (Wikipedia).

- When an individual approaches his job as a calling, then he focuses on the work itself. He will then work less for his financial gain or career advancement than for the fulfillment the work brings (Wikipedia).

- People who desire totally involving jobs that offer opportunities for responsibility, freedom and recognition (Weightman 1999:170). Individual probably has a need to be recognized appropriately for his or her expertise and contribution (Kung 2008).

- To some working environment is very vital regarding safety, health and wealth. Physical security, location heating, noise and professionalism are all important contributors. Ensuring that the environment is complying with all legislation and listening to employee complaints is important here (Howe 2003).Good workplace, safety usually goes with good management, high productivity and satisfied workers (Gruen 2004). Solving problems commensurated with a positive feedback is a vital issue for job satisfaction. 
- For many employees the opportunity for social interaction, with friendly coworkers and supervisors add significantly to the dimension of job satisfaction. Whether there is praise, good listening skills or a flaxen attitude, the manager will affect the satisfaction level (Howe 2003).

- Some employees identify him strongly with the employing organization. Perhaps it is the mission or vision of the organization. An employee is unhappy with his or her particular job; the employee may view this as a 'temporary' condition due to high satisfaction with the organization as a whole and remain loyal (Howe 2003).

Some people moderates wage and salary demands for happier working lives (Gruen 2004). By individual differences, we need to realize how these different people can be understood and manipulated. We are complex and that we all have a different point of view which needs, to be appreciated if we want to influence each other's behaviours. We all differ in our interests, attitudes and needs and that will affect how we react to different aspects of the job (Weightman 1999: 155\&170). Various facets of job-satisfaction have made it a multidimensional concept. For sustaining personnel in an organization, all the dimensions have to be keenly considered by the management.

\section{FACTORS OF JOB DISSATISFACTION}

Someone may have high expectation about an ideal job where he may be motivated, inspired, respected and well paid. He may start as his dream job and for sometime love it. But gradually he may find harder and harder to get through it then he will be dissatisfied. Following are the reasons why a person may not be completely satisfied with his job:

- Conflict between co-workers

- Conflict with supervisor

- Not being appropriately paid for what he does

- Not having the necessary equipment to become successful

- Lack of opportunities for promotion

- Having little or no say in decisions that affect a person

○ Fear of losing the job through downsizing or outsourcing.

Most of the human resource practitioners and leaders of organizations would instinctively say that people leave because there are better opportunities elsewhere, poor management, heavy workload, insufficient support by management, insufficient recognition (Howe 2003).

Sometimes it is the job itself that causes dissatisfaction. For example, the work may be dull or ill suited to one's interests, education and skills. Jobs with too little challenge, repetitive tasks are also deemed boring, frustrating and can produce feelings of failure. People who are uncertain about where they stand with their current employer are receptive to the lure of another organization (Howe 2003). Changes in machines, equipment processes and work layout affect the actual work methods, systems and procedures involved in carrying out the work (Weightman 1999: 56). With this technological change if training is not imparted change will lead to job dissatisfaction. Organizations that are growing suffer when they do not allocate necessary attention and financial resources to their human capital (Howe 2003).

Karl Marx formulated the concept 'Alienation'. It is about the separation of people. In organized work that we are cut off from important decisions, people and outcomes we can feel the work we do is alien and oppressive- that is, we are alienated (Weightman 1999: 180181). Blauner (1967) argued that alienation consists of four conditions or states powerlessness, meaninglessness, isolation and self-estrangement:

○ Helplessness comes when people feel controlled by others. 
- Meaninglessness comes when people do not understand the co-ordination or purpose of their work.

- Isolation is where people do not feel they belong.

○ Self-estrangement is when people do not feel involved with their work (Blauner 1967).

All the signs of alienation ultimately lead to job dissatisfaction. Management should be careful about whether there are indications of disaffection amongst the personnel when the job holders are frustrated, the express emotion of loneliness, are not committed to the organization then management should investigate the situation to prevent job dissatisfaction.

Affects of job dissatisfaction are detrimental to organization sometimes even devastating for the organization. 'Stress mounts when work is no longer satisfying'. Employees who are dissatisfied with their jobs tend to behave in ways that can be detrimental to the organizations these workers are likely to experience higher rates of turnover, absenteeism, tardiness and, more accidents, strikes, grievances, sabotage(Byars and Rue 2000: 304). When dissatisfaction spreads in the organization itself then the employee is more likely to resign (Howe 2003). Job dissatisfaction leads to high turnover. High turnover leads to low staff morale, organizational instability and a loss of productivity. It is well documented that losing an employee is a very expensive occurrence. There is a recruiting cost, interviewing, reference checking, testing, orientation cost and more. There is also the cost of losing experience. Clients lose their contacts and workers lose co-workers, both of which result in productivity loss (Howe 2003). Job dissatisfaction is one of the great causes of this sort of loss experienced by the organization.

\section{WHAT LEADS TO JOB SATISFACTION}

Job satisfaction is more an individual state of mind. Performance leads to rewards that result in a certain amount of satisfaction. Alongwith rational pay, opportunities for learning and advancement, style and quality of management, perceived long-range opportunities are important for all working people. Categorically most of the female officials and employees give importance to flexible work schedules, child care facilities (Byars and Rue 2000:303and304). Following are some of the ways that may lead to job satisfaction:

- There are strong synergies between job satisfaction and productivity and the higher the skill level, the stronger the effect. Improving the market for work satisfaction will boost productivity (Gruen 2004). Improving one's job skills will enhance confidence to accomplish a task successfully which will give satisfaction.

- Availing training opportunity for a different task will combat boredom. Once the training is complete switching back and forth can be done.

- Taking advantage of work breaks will break the monotony. For instance, reading, listening to music, going for a walk, writing a letter, communicating with a friend would be helpful.

$\circ$ In the midst of a working day, relaxation is necessary to confront the rest of the day with enthusiasm by being rejuvenated.

- Being bored by doing repetitive tasks, asking supervisor for a new challenge would help to gain renewed energy.

- The importance of good old-fashioned day-to-day feedback should never be underestimated. Regular performance reviews are essential communication tool to keep staff informed and focused. Giving feedback, in a constructive manner, enhances respect for the employment relationship (Howe 2003).

- By praising and rewarding, recognition should be provided to gain commitment.

- Changing one's attitude about work would not necessarily happen overnight. But stopping negative thinking, learning from ones mistakes, using positive thinking to reframe one's 
thoughts about his job would be beneficial. Gratitude can help a person focus on what is positive about one's job .

- To understand an individual's general attitude toward his or her job, positive or negative, is vital in understanding relationship to employee productivity, absenteeism and turnover rates. The most common assessment tool in measurement of job satisfaction is an employee survey, which should be conducted on regular basis (Howe 2003).

- Formulation and implementation of a fair pay policy and procedures are likely to be appreciated by all which would ensure greater job satisfaction.

- Human resources (HR) should be dealt professionally to understand turnover or retention problems. An HR professional can create and conduct exit interviews, review policies, procedures, employee handbooks and benefits (Howe 2003).

- An individual must think about what motivates and inspires him. He may even take the assistance of a career counselor to complete a formal assessment of his interests, skills and passions and then explore some strategies to increase his job satisfaction (www.mayoclinic.com).

In 1999 Jane Weightman, the author in the book titled 'Managing People' has expressed her views regarding 'fundamental characteristics of people', 'changing world of work and optimizing people's contribution'. Keeping in view the core theme job satisfaction the book has been reviewed thoroughly and several measures have been recommended for ensuring job satisfaction for managing people at work. The following section contains such measures:

- In an organization by understanding and tolerating individual differences we are more likely to get a co-operative, productive effort from those we come into contact with. By understanding why an individual may behave differently we are more likely to be able to accept the difference or to find a convincing way of helping him or her to change. Our view of personality will also affect how we interact with people (Weightman 1999:16). According to Hans Eysenck a British psychologist those with an introverted personality are naturally highly aroused so any extra stimulation sends them into a state of anxiety. By contrast extroverted people are in a low state of arousal and consequently need a lot of stimulation to get them going (Eyesenck 1962). Considering individual differences and personality profile, people should be dealt by superiors for ensuring job satisfaction.

- American psychologist B F Skinner emphasized the external control of behaviour: we behave in the way we do because of our history of reinforcement or rewards (Skinner 1953). By studying observable behaviour and the effect of different rewards given at different times, the behaviourists have built up a detailed technology for specific learning. The idea is to make the instructions as clear as possible and when the correct response is elicited a reward is given: it may be 'well done' or something more concrete. The process of manipulating people's behaviour by adjusting the instructions, task and reward is called 'behaviour modification' which is important for job satisfaction. The only task is to analyse the desired behaviours and reinforcements in sufficient detail and with enough accuracy for individuals to be motivated to behave appropriately (Weightman 1999: 20-21). Through consulting and observing the impact of rewards and reinforcement pattern of each personnel behaviour can be moulded in favour of the organization and at the same time the level of job satisfaction may be elevated.

- Carl Rogers advocated individuals take responsibility for themselves and their actions (Rogers 1967). The enthusiasm for participation in decision making, ownership of ideas, autonomous work groups and developing potential all fit within humanistic psychology (Weightman 1999:22). All these self-management strategy are important for people possessing self-actualising personality.

- According to Kelly we each see things differently and interpret things differently using our own dimensions and models; this means we each construe the world differently (Kelly 1955). There are individual differences because we organise the incoming message into our stable 
view of the world we make it seem stable to us (Weightman 1999: 24-25). For ensuring jobsatisfaction this perceptual difference should be keenly considered.

- Changing our stereotypes and prejudices is not easy. Changing other people's stereotypes and prejudices is even more difficult, but we need to try where these are inappropriate. The better we know ourselves the easier it is to see others accurately. One's own character affects what one sees in others. The accuracy of our perception depends on our sensitivity to the differences between people. Trying to develop a sensitivity about people that looks below superficial differences is the beginning of wisdom and credibility in managing people (Weightman 1999:31). If people's negative attitude at workplace, prejudices can be changed they are likely to be satisfied.

- Attitudes give a base or framework for classifying and interpreting new information. Depending on our past experiences of rewards and negative experiences we hold different attitudes to people and experiences (Katz and Kahn 1978). Developing positive attitude is important for job satisfaction.

- Technological change demands particular skill which affects the status and pay of the operator. When new technology is introduced managing change is important as the workers may not only be asked to work differently but the technology may also be affecting the nature of their relationships with each other. Organization aims to create an efficient, effective and creative workplace. Using office design, technology, changes in working practices and the workplace culture may help to achieve the aim (Weightman 1999:57). This congenial working environment is significant for enhancing job satisfaction.

- The balance between the organization and the individual has been summed up in the phrase "psychological control" (Mumford 1972). This contract includes factors that affect feelings, motivation and loyalty. It itself is affected by the climate of the organization and the nature of management style, which can be coercive or co-operative or a calculated style in the middle (Weightman 1999:60-61). For creating a congenial environment and ensuring job satisfaction intermingling organizational goal and individual goal is crucial.

- Establishing informal relationships at work is of varying importance to different people (Weightman 1999:66). This relationship may arise enthusiasm to varying degree. Recognition and provision of informal relationship in the organization is important.

- Increasing skill and moving from one job to another may reduce boredom (Weightman 1999:66). This job rotation may be a source of job satisfaction.

- Through job enrichment broadening the responsibilities and increasing individual autonomy for decision-making is important (Weightman 1999:68). There are many challenging people who desire job enrichment for their self-satisfaction.

- Power made legitimate by position or expertise is called authority. The formal organization charts, job titles and pay structures provide in authority legitimacy. Responsibility without the authority to get things done is utterly frustrating for the people involved (Weightman 1999:156,158,160). With responsibility a person's authority should be acknowledged.

- Delegation means entrusting some degree of authority and responsibility to others. Mullins suggests that delegation is founded when someone is given the right to make decisions and take actions and to perform certain duties (Mullins 1996:570). To a certain degree power should be delegated to make the personnel feel that they are given importance.

- Creating a network of contacts is crucial to getting things done easily (Weightman 1999:160). Through effective network personnel will be able to communicate with anyone, anytime and solve problems easily.

- Attempts to pre-empt elements of alienation found within organizations include trying to empower staff, setting reasonable objectives, valuing staff and engendering commitment (Weightman 1999:182). When people at work feel they are not alienated, without their participation no decision would be imposed on them they would be satisfied.

- The meeting may be the focus of decision-making with all the appropriate people present to enable the decision to take place or, as often happens; prior discussions completed leading to 
decisions and the meeting merely ratifying them (Weightman 1999:163). Taking active participation in these official meetings ensure job satisfaction. People must feel they have a voice, their voice is heard.

- Motivation is a drive, within a person to try to achieve a goal, to meet a want or need. We can only see the consequences of someone's inner motivation. In western cultures, we tend to emphasise individuality and achievement whereas in many Eastern cultures there is an emphasis on the family and group achievements and fitting in and being accepted is valued highly. These affect what makes one motivated to work for (Weightman 1999:168-169). To some person motivation brings job satisfaction.

- It is very essential to understand the needs and objectives of peers and subordinates and to arrive at some sort of equitable arrangement that their needs, as well as the organization's needs, will be met (Weigthman 1999:169). Effective measures may take for grievance handling and actions should be taken for satisfying the needs of people at work.

- Understanding what motivates people at work will also suggest appropriate rewards for them in response to their contribution. They include: pay for time; by results; for merit; performance related; profit related other benefits-holidays; pensions; sick pay; insurance; vouchers; and health club membership at a discount and other financial benefits (Weightman 1999: 177). Pay arrangements are the most tangible expression of the working relationship between employer and employee (Weightman 1999: 182). When people would perceive reward as just and fair then spontaneously level of job satisfaction would enhance.

- Credibility is the word used to describe the prerequisite ability that one needs to get things done. Those with high credibility are worthy of belief, trustworthy, convincing and respected. They can listen to and can achieve things willingly and quickly (Weightman 1999:157). Therefore, credible manager can be given the responsibility to promote job satisfaction.

By taking proactive actions to improve job satisfaction, a supervisor or a manager can help reduce turnover and retain key staff (Howe 2003). Sustaining dissatisfied people at work is really tough. For optimum, utilization of people's effort ensuring job- satisfaction is very significant.

\section{CONCLUSION}

As a key concern of Human Resource Management, job satisfaction has drawn the attention of business magnets, mangers and social scientists. For ensuring job satisfaction task demand and individual demand should be well-balanced. Accordingly job requirement and person need satisfaction should be fulfilled proportionately. When individual lacks faith toward organization then eventually job satisfaction diminishes.

Next to our health and relationships with close family and friends, nothing matters more to us than the quality of our working life. Through conducting periodic confidential employee surveys employee's can express opinion about workplace issues and others that matter most (Gruen 2004). Yearly surveys give employees a constructive outlet for voicing their concern and frustrations (Hollenbech and Wright 1996:238). If management considers personnel welfare issues and opinions with integrity, then the surveys would be meaningful and contribute a lot for improving the quality of working life. If management is not committed for ensuring job satisfaction and remains indifferent to employees, people at work would merely be satisfied rather they would be discontent. After a certain period this discontentment or dissatisfaction would become detrimental to management and overall to the organization.

As Gruen comments, 'Those who want a balance in their lives between work and family commitments may say goodbye to the endless battle with hostile corporate cultures and join workplaces of like mind. Those of a more Darwinian bent may continue the struggle for survival at the Darwinian end of town (Gruen 2004). Therefore, for managing people at 
work ensuring job satisfaction is crucial for the survival of the organization in a competitive market, as well as for sustaining and influencing personnel to give their maximum effort.

\section{REFERENCES}

Ahmed AA, Khan W and Siddique MN. 2011. Banking Sector HR Practices on Perceived Employee Performance: A Case of Bangladesh Prime Magazine, 31, 8-12.

Ahmed, M. (2015). The Role of Self-esteem and Optimism in Job Satisfaction among Teachers of Private Universities in Bangladesh. Asian Business Review, 1(2), 114-120.

Alam, S. (2015). Factors Affecting Job Satisfaction, Motivation and Turnover Rate of Medical Promotion Officer (MPO) in Pharmaceutical Industry: A Study Based in Khulna City. Asian Business Review, 1(2), 126-131.

Blauner R (1967) Alienation and Freedom: The factory worker and his industry. Chicago: University of Chicago Press.

Byars, LIoyd L and Rue, Leslie W (2000) Human Resource Management $6^{\text {th }}$ ed. USA: McGraw-Hill Higher Education.

Christen, M., Iyer, G. and Soberman, D. (2006). Job Satisfaction, Job Performance, and Effort: A Reexamination Using Agency Theory, Journal of Marketing, January, Vol. 70, pp. 137-150

Davis, K. and Nestrom, J.W. (1985). Human Behavior at work: Organizational Behavior, 7 edition, McGraw Hill, New York, p.109

Eysenck H J (1962) Know your own IQ. Harmondsworth: Penguin.

Gruen, Nicholas (2004) www.smh.com.au

Hackman J R (1987) 'Work design' in steers RM and Porter LM eds, 4th end. Motivation and Work Behaviour: London: McGraw-Hill.

Herzberg, H. F. (1976). Motivation-Hygiene Profiles, p. 20

Hollenbech, Noe and Wright, Gerhart (1996) Human Resource Management: Gaining a Competitive Advantage, USA: Irwin/McGraw Hill

Hoppock, R. (1935). Job Satisfaction, Harper and Brothers, New York, p. 47

Howe, Teresa (2003): www.charityvillage.com

Katz D and Kahn R L (1978) The Social Psychology of Organizations. $2^{\text {nd }}$ ed. New York: Wiley.

Kelly G (1955) The Psychology of Personal Constructs, New York: Norton

Kung, Jocelyn (2008) www.hrdq.com

Lawler, E.E. III and Porter, L.W. (1967). The Effect of Performance on Job Satisfaction, Industrial Relations, pp. 20-28.

Locke, E.A. and Latham, G.P. (1990). A theory of goal setting and task performance, Prentice Hall, p.4

Maslow A H (1954) Motivation and Personality. New York: Harper and Row.

Mullins L J (1996) Management and Organisational Behaviour, London: Pitman.

Mumford E. (1972) 'Job Satisfaction: a method of analysis', Personnel Review.

Nasima, M., \& Alam, N. (2015). Job Satisfaction among Female Fculties of Different Public and Private Universities in Bangladesh: A Comparative Analysis. ABC Journal Of Advanced Research, 4(1), 16-26.

Rogers C (1967) On Becoming a Person. London: Constable.

Rue, L.W. and Byars, L. (2003). Management, Skills and Application, 10 ed., McGraw-Hill/Irwin, New York, p.259

Spector, P.E. (1997). Job satisfaction: Application, assessment, causes and consequences, Thousand Oaks,CA,Sage Publications, Inc

Steers RM and Porter LW eds. (1991) Motivation and Work Behaviour: $5^{\text {th }}$ end. London: Mcgraw-Hill.

Vroom, V.H. (1964). Work and motivation, John Wiley and Sons, New York, p.99

Weightman, Jane (1999) Managing People. London: Institute of Personnel and Development House, Camp Road.

Wikipedia, the free encyclopedia, http:/ /en.wikipedia.org/wiki/Job satisfaction www.mayoclinic.com 